\title{
Práticas percussivas nas aulas de música do ensino fundamental
}

\section{Practices of percussion in elementary school music classes}

Teresa Mateiro ${ }^{1}$ Beatriz Woeltje Schmidt ${ }^{2}$ 


\section{Resumo}

Para esta pesquisa foram utilizadas informações já existentes em vídeo que, depois de analisadas, contribuíram para compreender como a percussão é trabalhada nas aulas da disciplina curricular Artes/Música. Das 40 aulas gravadas em seis escolas da rede pública de ensino dos estados de Santa Catarina e Paraná, sete que apresentavam atividades com percussão foram selecionadas, tendo sido analisadas a partir de categorias relacionadas aos processos de ensino e aprendizagem: imitação e escuta, música em conjunto, percussão como forma de musicalização e desenvolvimento psicomotor. Constatou-se que a percussão foi utilizada nas sete aulas como um meio para desenvolver a musicalização e a psicomotricidade. Atividades de imitação e escuta, bem como a prática coletiva estiveram presentes em três aulas. Concluise que as atividades com percussão nas aulas de música apresentaram uma grande quantidade de possibilidades e variedades de instrumentos, porém ainda são poucos os professores que se utilizam dessa prática.

Palavras-Chave: escola pública, ensino de percussão, vídeo.

\section{Abstract}

In this research information from existing video recordings was used, and, after being analyzed, contributed to the understanding on how percussion functions in classes of the curricular subject Arts/Music. Of the 40 lessons recorded in six public schools in the states of Santa Catarina and Paraná, seven containing percussion teaching were identified and selected, then analyzed based on categories related to teaching and learning processes: listening and imitating, playing together, percussion supporting musical knowledge and psychomotor development. It was found that percussion was used in the seven classes as a means to develop music knowledge and psychomotricity. In three classes imitation and listening activities, as well as music making as collective practice, were present. We conclude that activities with percussion in music classes displayed a lot of possibilities and exhibited a vast variety of instruments, but still few of the teachers made use of this practice.

Keywords: public school, percussion teaching, video

ISSN: $1808-3129$

1 Professora Dra. Na Universidade do Estado de Santa Catarina - Udesc, Brasil. teresamateiro@gmail.com

2 Brasil. beatrizwschmidt@gmail.com 


\section{Introdução}

O objetivo deste trabalho foi investigar de que forma a percussão está sendo trabalhada em aulas de música do Ensino Fundamental em escolas públicas de Florianópolis, Curitiba e Microregião de Itajaí, discutindo estratégias de ensino e aprendizagem utilizadas pelos professores. Este estudo faz parte de um projeto de pesquisa mais amplo ${ }^{3}$ que tem como principal objetivo indagar e refletir sobre o ensino de música como conteúdo curricular obrigatório, verificando como as aulas são planejadas e levadas a cabo, com o intuito de produzir conhecimento acerca das condições, causas e formas na construção do conhecimento musical e pedagógico que se está realizando na prática.

Pesquisas relacionados ao referido projeto têm sido desenvolvidas com diferentes perspectivas: Madeira (2012), Madeira e Mateiro (2013) discutem aspectos apontados por uma professora de música de escola pública da cidade de Florianópolis, que motivaram os alunos do $4^{\circ}$ ano a participarem das atividades propostas em sala de aula; Mateiro e Egg (2013) investigaram de que forma a atividade do canto se desenvolveu em uma turma de 6ㅇa ano de uma escola pública da cidade de Curitiba; Vechi (2015) buscou conhecer e compreender como três professores licenciados em música da Microregião do Vale de Itajaí analisaram sua formação e suas práticas com o canto em sala de aula; e, Madeira (2015), partindo da concepção do professor pesquisador, investigou quais foram os aspectos da aula de música indicados por um professor licenciado quando analisou e refletiu sobre a própria prática. Esses trabaIhos utilizaram a técnica de observação no contexto da disciplina curricular Artes/ Música como a principal fonte de informação.

Somando todas as aulas observadas chegou-se a um total de 50 entre as quais 40 foram gravadas em vídeo e sete constituíram a fonte primária de informação para a realização desta pesquisa por apresentarem atividades de percussão - corporal e instrumental - que foram propostas e desenvolvidas durante essas aulas de música. Consideram-se como instrumentos de percussão aqueles que são percutidos por meio de uma membrana, barra de metal, madeira ou outro material rígido, além daqueles que são executados sacudindo-os como os membranofones que produzem som por meio de uma membrana e os idiofones, nos quais o som é produzido a partir do seu próprio corpo em vibração (STANLEY, 1994). Além desses instrumentos, neste estudo a percussão corporal também foi considerada como elemento de prática percussiva.

A aprendizagem musical com instrumentos de percussão variados normalmente ocorre mediante processos de escuta e imitação, processos esses que serão discutidos a seguir no âmbito da sala de aula no contexto escolar. Destaca-se que o ensino de música por meio da percussão também proporciona o desenvolvimento da coletividade e socialização, e de capacidades psicomotoras, além de transformar a linguagem rítmica dos educandos, temas abordados ao longo deste artigo.

3 Projeto intitulado Aulas de Música: Perspectivas Culturais e Educacionais, coordenado pela Profa Dr $^{a}$ Teresa Mateiro, com participação dos membros da equipe do Grupo de Pesquisa Educação Musical e Formação Docente (CNPq/UDESC), e desenvolvido com auxílio financeiro da FAPESC. 


\section{Percussão na sala de aula}

Compreender práticas musicais na escola como práticas sociais permite entender as relações do cotidiano com o fazer musical. Dessa forma, possibilitar que a aula de música seja um espaço sociomusical e relacional de construção do sujeito, faz com que o caráter social e o musical sejam fatores indissociáveis (SOUZA, 2014, p.12). As práticas percussivas predispõem desse caráter de socialização levando em consideração a diversidade de instrumentos e a contribuição para as práticas coletivas. Small $(1989$, p.218) acrescenta que fazer música através da percussão ou de práticas coletivas, faz com que os indivíduos envolvidos na performance desenvolvam seu aspecto comunitário em música. Ademais, estarão firmando vínculos acrescidos de valores, vivências e relações. As crianças e o professor da turma ali presentes farão parte da mesma performance, criando laços, confiança e um forte senso de coletividade.

Além do fator de socialização, conforme Paiva (2004, p. 24), "a aprendizagem musical através dos instrumentos de percussão acontece de diferentes maneiras, em diferentes manifestações musicais e em diferentes contextos e grupos sociais". O universo percussivo possibilita aprender variados instrumentos e, consequentemente, desenvolver diversas técnicas, manuseios e movimentos corporais, possibilitando que o aluno transforme sua linguagem rítmica. De acordo com Rossatto e Camargo (2010, p.8), a percussão corporal é uma dessas formas possíveis para o ensino de música que, além de desenvolver a capacidade psicomotora das crianças, também aperfeiçoa o sistema sensorial. $O$ aluno ao usar o seu corpo como um instrumento de percussão, poderá explorar sons, variação de timbres e texturas a partir da voz, palmas, estalos de dedos, batida dos pés, batidas no peito, entre outros efeitos.

O processo de ensino e aprendizagem por meio da prática de musicalização, segundo Chiarelli e Barreto $(2005$, p.2), permite que a criança "conheça melhor a si mesma, desenvolvendo sua noção de esquema corporal", além de possibilitar a comunicação com o outro. Um conjunto completo e complexo de ações fazem com que a criança desenvolva o senso rítmico e a coordenação motora, fatores importantes para a aprendizagem musical como um todo. Para os autores o "ritmo tem um papel importante na formação e equilíbrio do sistema nervoso" (p.3).

\section{Imitação e escuta no ensino e aprendizagem musical}

Os estudos sobre imitação nas etapas iniciais do desenvolvimento da criança tem sido apontados sob diferentes perspectivas teóricas, principalmente, a piagetiana e a vygostkyana (ver MOURA; RIBAS, 2002, p.207). No campo da educação musical foram encontrados trabalhos sobre imitação que descrevem aspectos do desenvolvimento para a aprendizagem de acordo com educadores consagrados como, por exemplo, Piaget (DECKERT, 2008; WEILAND; VALENTE, 2007; SLOBODA, 2008). A capacidade imitativa de canções, incluindo a análise da reprodução do ritmo, contorno melódico e tonalidade, tem sido estudada para melhor compreender como ocorre o desenvolvimento musical. Para este trabalho, considerou-se o conceito de imitação 
associado à ideia de repetição, imitação em tempo real.

A imitação faz parte dos processos de compreensão e interação no aprendizado musical. Para Balthazar e Freire (2012, p.8), cada indivíduo se espelha no outro e utiliza-o como modelo para seguir seus movimentos e ações. Na aprendizagem musical esse processo está presente em vários momentos, tais como: imitações de gestos, movimentos e posições, mas também respostas a estímulos sonoros. O processo de imitação em tempo real pode ser analisado através da descoberta dos neurônios-espelhos os quais são ativados pela observação de uma ação, permitindo que o significado dessa ação seja compreendido automaticamente (LAMEIRA; GAWRYSZEWSKI; PEREIRA, 2006, p.124). A compreensão acerca do funcionamento dos neurônios-espelho tem se tornado essencial para o desenvolvimento musical, entretanto, não é o escopo deste trabalho.

No processo de ensino e aprendizagem a escuta faz-se importantíssima, não apenas para o processo de imitação em tempo real, como também em outras atividades desenvolvidas durante a aula de música. Segundo Schafer (1991, p.67) quando há a possibilidade de "abrir os ouvidos" para todos os sons do mundo, o fazer musical torna-se resultante de um processo muito mais criativo. Com isso, a escuta passa a ser importante tanto para a formação do educador musical quanto para a aprendizagem dos alunos.

\section{Revisando a literatura}

Para a revisão de literatura, inicialmente, foi consultado o Índice de Autores e Assuntos (MATEIRO, 2013) e, posteriormente, foram feitas buscas nas Revistas e Anais da ABEM, assim como no portal e nos periódicos da CAPES, a partir das palavras-chave: percussão, ensino, educação musical e aprendizagem. Foram encontrados seis trabalhos aproximados ao tema sobre a percussão na educação básica: Paiva (2004), Freitas (2008), Müller (2005), Marcelino (2014), Schrader (2011) e Santos (2013).

Paiva (2004) ao analisar métodos de percussão e bateria, discute as relações entre a percussão e a aprendizagem integradora, além das técnicas instrumentais tradicionais, buscando o contexto e uma abordagem de integração entre os estudantes inseridos na proposta. Tanto em aulas individuais como em grupo, entre instrumentos de percussão variados, discurso musical dos alunos e do professor, a integração se faz. Segundo o autor, os alunos que conseguiram participar de forma integrada relataram que o desenvolvimento musical foi muito positivo com resultados diretamente na performance, integrando diversos instrumentos de percussão e, ainda assim, podendo estar relacionada com o discurso musical do professor e dos estudantes.

Nessa linha de análise de métodos encontra-se também a pesquisa de Freitas (2008) que busca refletir sobre a importância da gestualidade e da corporalidade nas relações de ensino e aprendizagem dos instrumentos de percussão. A percussão quando trabalhada em grupo, amplia a compreensão musical de todos envolvidos na atividade tendo o gesto como um meio facilitador para o ensino e ainda aproxima as expressões musicais originais da cultura popular brasileira. Para a autora, o gesto influencia diretamente na qualidade da performance, trabalhado nas dinâmicas, acentos, articulação, todos moldados à qualidade e dimensão do gesto. Com isso, se 
há um grupo de percussão e todos estão tocando com um gesto preciso, no mesmo tempo, fluência e expressividade, percebe-se a importância deste caráter diretamente ligado à performance do grupo.

Para uma performance qualificada e atrelada a diversos sentidos, de acordo com Müller (2005), é importantíssima a investigação da relação entre as vivências dos alunos no seu cotidiano e dentro de sala de aula. A pesquisa desenvolvida por Müller focalizou o sentido da performance musical nas oficinas de percussão oferecidas em um projeto de extensão do Departamento de Música da UDESC (ver também MÜLLER; HAHN, 2005). O trabalho, fundamentado nas ideias de Small (1989), considera que a performance em si não se refere aos saberes e habilidades, mas sim ao momento proporcionado, no aspecto vivencial da música e de seu caráter comunitário.

Marcelino (2014) desenvolveu um trabalho dentro do grupo de maracatu Arrasta Ilha, apresentando cinco dinâmicas de aprendizagem musical categorizadas como: "tirar de ouvido", encontros casuais e organizados, observação e imitação, onomatopéias solfejadas e aprender "osmoticamente". O último termo foi criado pelos integrantes do grupo que o definiu como sendo uma maneira natural de expressar o aprendizado e a absorção dos elementos. O referencial teórico da pesquisa combina o conceito de aprendizagem informal citando Lucy Green e o conceito de comunidade de prática de Etienne Wenger. As práticas e dinâmicas de aprendizagem musical tornaram-se significativas por um interesse em comum: o grupo maracatu Arrasta Ilha.

O desenvolvimento das práticas percussivas na Universidade Federal do Ceará, focalizando a expressão musical e estratégias de ensino e aprendizagem de grupos envolvidos nessas práticas são descritas por Schrader (2011). O autor busca entender como essas práticas percussivas se desenvolvem no meio acadêmico na formação de futuros professores de música no curso de licenciatura. A proposta do pesquisador foi unir o interesse que os alunos manifestavam por percussão a outras disciplinas e projetos. Para isso, foram feitas análises sobre o conceito de "experiência significativa" de Larrossa (2012) com as turmas de Oficina de Percussão I e II. O Mestre e ritmista Descartes Gadelha aproximou o contexto acadêmico com o contexto da percussão na comunidade de Fortaleza e o Grupo de Tradição Cearense. O Grupo Brincantes Cordão do Caroá ainda participaram da investigação como importantes difusores das manifestações da música popular.

Outro grupo de música percussiva da Universidade Federal do Ceará, o Casa Caiada, foi investigado por Santos (2013), no período de 2009 a 2012, com o objetivo de analisar o processo contínuo da formação humana e musical de cinco integrantes. De acordo com a autora, o processo de ensino e aprendizagem por oralidade, audição, improviso, observação e imitação vocal e instrumental, tem a corporalidade como característica fundamental. Os sujeitos entrevistados apontaram as atividades de apreciação musical, as dinâmicas de musicalização (oralidade, improviso e corporalidade), a colaboração entre amigos, as reflexões e a construção do espetáculo percussivo "Sons da Casa" como as principais experiências em sua formação. Santos afirma que "o processo de formação humana e musical aconteceu de forma significativa e produtiva na vida pessoal de cada um que expressou o desenvolvimento tanto na questão técnica e musical quanto nas relações sociais e de crescimento 
pessoal" (p.122).

$\mathrm{Na}$ busca por trabalhos sobre percussão relacionados à educação musical e aos processos de ensino e aprendizagem, percebeu-se que muitos pesquisadores se preocupam com o registro dos ritmos e das notações, muitas vezes produzindo métodos, livros ou apostilas (JACOB, 2003; SAMPAIO; BUB, 2014; FRUNGILLO, 2003; $B O L A ̃ O, 2003)$. Ainda que nos últimos anos note-se um crescimento em pesquisas sobre o ensino coletivo de instrumentos, trabalhos esses que têm aproximação com o tema deste estudo, as áreas como a percussão e a bateria possuem produções bastante restritas, conforme aponta Souza (2012).

\section{O vídeo na pesquisa qualitativa}

Para esta pesquisa foram utilizadas informações já existentes em vídeo que, depois de analisadas, contribuíram para compreender como a percussão é trabalhada nas aulas da disciplina curricular Artes/Música de seis escolas da rede pública de ensino dos estados de Santa Catarina e Paraná. Os vídeos, que foram gravados durante 40 aulas de música realizadas em diferentes escolas públicas, foram cedidos pelos integrantes do Grupo de Pesquisa Educação Musical e Formação Docente tornandose, assim, a principal fonte de dados para o desenvolvimento deste estudo.

$\mathrm{Na}$ pesquisa, o vídeo tem sido utilizado, principalmente com duas finalidades. A primeira é a observação feita in loco, em que a lente da câmera capta imagens, cenas e situações, passando o vídeo a ser um método de observação indireta de coleta de dados. O vídeo tem uma função bastante clara de registro de dados sempre que algum conjunto de ações humanas é difícil de ser descrito compreensivelmente por um único observador enquanto ele está atuando. É o registro tecnológico da observação de um acontecimento real que acontece em seu contexto natural. Com esse material, o pesquisador deverá realizar diversas tarefas: exame sistemático do corpus de pesquisa, criação de um sistema claro de anotações e a análise das informações coletadas (LOIZOS, 2004, p.149). Muitas pesquisas na área educacional têm usado a videogravação, pois conforme aponta Pacheco (1995, p. 91) "proporciona a recolha de incidentes que não são anotados pelo professor, a visualização dos alunos em diferentes momentos e situações, a captação da totalidade da conversação da aula, além de fornecer um material para tratamento posterior".

A segunda finalidade refere-se à utilização do vídeo para realizar entrevistas de estimulação de recordação, ou seja, a gravação de uma aula é assistida pelo professor estimulando-o a pensar sobre suas práticas pedagógicas. A partir das imagens vistas, o professor recorda, tenta analisar e coloca seu ponto de vista sobre o que assistiu (PACHECO, 1995, p.74). Trabalhos na área da educação musical que utilizaram essa técnica para saber como os professores percebem sua atuação podem ser citados como, por exemplo: Beineke (2000), Uller (2012), Madeira (2012; 2015) e Moreira (2014). Beineke e Madeira exibiram aulas integrais para serem assistidas e comentadas pelos professores enquanto Uller e Moreira selecionaram pequenos trechos das aulas dos professores que estavam sendo entrevistados.

Vídeos já existentes, não produzidos especificamente para este estudo, foram as principais fontes de informação, sendo utilizados para fins de análise, usando-se 
assim os princípios da vídeo-análise como um recurso investigativo. De acordo com Leitão, Teixeira e Rocha (2011, p.21) a vídeo-análise "consiste em fazer uma tomada de vídeo de um fenômeno ou experimento e depois executar uma análise minuciosa sobre este vídeo". Essa análise, normalmente, é realizada com programas que oferecem diversos recursos de tratamento do vídeo. Não se usaram programas computacionais neste caso, mas o princípio de selecionar um aspecto registrado em vídeo para analisá-lo detalhadamente.

A videogravação, conforme destacam Garcez, Duarte e Eisenberg (2011, p.256), vem sendo bastante utilizado em pesquisas qualitativas, porém, ainda possui baixa produção bibliográfica sobre análise desse material. A dimensão visual da realidade social, incluindo fotografias, filmes e filmagens em vídeo, conforme aponta Bohnsack (2010), tem tido pouca atenção nas investigações qualitativas, ao contrário da interpretação de textos que se mantém como a principal abordagem. Entretanto, continua o autor: "falar de um entendimento através de imagens significa que nosso mundo, nossa realidade social, não é apenas representado por imagens, mas também constituído ou produzido por elas" (p.115).

\section{Aulas de música gravadas em vídeo}

Aulas de música de diferentes escolas foram observadas e registradas em vídeo por Madeira (2012; 2015), Vechi (2015) e Mateiro e Egg (2013), com o principal objetivo de indagar e refletir sobre o ensino de música como conteúdo obrigatório curricular da disciplina de Artes. No ano de 2012, foram observadas cinco aulas de duas

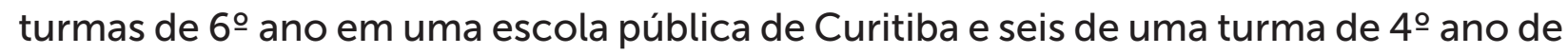
uma escola pública de Florianópolis (Tabela 1). Em 2014, foram observadas 34 aulas em quatro escolas públicas (13, 7, 8 e 6 aulas, respectivamente), sendo uma delas em Florianópolis e as demais na região do Vale do Itajaí.

\begin{tabular}{|c|c|c|c|c|c|}
\hline ANO & TURMA & CIDADE & OBSERVAÇÕES & GRAVAÇÕES & REFERÊNCIAS \\
\hline \multirow[t]{3}{*}{2012} & $6^{\circ}$ ano $\mathrm{A}$ & \multirow[t]{2}{*}{ Curitiba } & 05 & 04 & \multirow[t]{2}{*}{ Mateiro; Egg (2013) } \\
\hline & $6^{\circ}$ ano $\mathrm{B}$ & & 05 & 04 & \\
\hline & $4^{\circ}$ ano $\mathrm{A}$ & Florianópolis & 06 & 05 & $\begin{array}{l}\text { Madeira (2012) } \\
\text { Madeira; Mateiro (2013) }\end{array}$ \\
\hline \multirow[t]{4}{*}{2014} & $4^{\circ}$ ano $\mathrm{B}$ & & 13 & 09 & Madeira (2015) \\
\hline & $4^{\circ}$ ano $\mathrm{C}$ & \multirow[t]{3}{*}{ Vale do Itajaí } & 07 & 06 & \multirow{3}{*}{ Vechi (2015) } \\
\hline & $5^{\circ}$ ano $\mathrm{A}$ & & 08 & 07 & \\
\hline & $5^{\circ}$ ano $\mathrm{B}$ & & 06 & 05 & \\
\hline & & Total & 50 & 40 & \\
\hline
\end{tabular}

Tabela 1: Gravações das aulas

Fonte: autoras 


\section{O material desta pesquisa}

Para esta pesquisa foram selecionados somente os vídeos referentes às aulas onde foram desenvolvidas atividades de percussão, ou seja, sete aulas. Estas foram entendidas a partir de quatro categorias que se complementam e estão intrinsecamente ligadas ao aspecto do processo de ensino e aprendizagem da percussão: imitação e escuta para aprendizagem, música em conjunto (aspecto coletivo), percussão como forma de desenvolvimento psicomotor e percussão como forma de musicalização. Estas categorias foram extraídas de trabalhos que apresentaram discussão relacionada à utilização de instrumentos de percussão em escolas básicas de ensino público e suas formas de ensino e aprendizagem. Selecionar essas categorias, a partir de alguns autores que discutem o ensino da percussão e outros elementos como percussão corporal e musicalização (FREITAS, 2008; PAIVA, 2004; ROSSATTO; CAMARGO, 2010; SANTOS, 2013; SMALL,1989), permite identificar com maior clareza qual a prática conduzida dentro do contexto de cada aula de música.

Nos cinco registros em vídeo feitos por Madeira (2012) foram gravadas aulas em que suas atividades focavam, principalmente, o trabalho de diversas canções com o acompanhamento de violão. Deste total de cinco aulas, não foram visualizados instrumentos de percussão ou qualquer atividade que trabalhasse elementos de caráter percussivo, razão pela qual esses vídeos não serão considerados neste estudo. Da mesma forma, na gravação dos oito vídeos de Mateiro e Egg (2013) não foram identificadas atividades com instrumentos de percussão, ainda que possam ser considerados como mais próximos ao universo percussivo por utilizar copos e palmas no processo de aprendizagem de unidades de compasso. As aulas centraram-se em atividades com flauta doce, desenvolvendo a iniciação à leitura musical, destacando elementos como pulsação e compassos.

De um total de nove gravações em vídeo, Madeira (2015) registrou aulas de música bastante diversificadas trabalhando aspectos como: instrumentos de sopro, a classificação e exploração da flauta doce, instrumentos de percussão, instrumentos de orquestra e instrumentos populares (jazz). Dessas nove aulas, somente em três foram apresentadas atividades com instrumentos de percussão trabalhando categorias de ensino e aprendizagem como: imitação e escuta para aprendizagem, música em conjunto (aspecto coletivo) e percussão como forma de musicalização.

Vechi (2015) registrou um total de dezoito vídeos em aulas de música de três escolas diferentes, onde foram trabalhadas atividades como: canto, flauta doce, boi-de -mamão, leitura musical, etc. Um dos professores em uma das escolas desenvolveu quatro aulas com atividades que envolviam instrumentos de percussão, assim como, o trabalho com percussão corporal para o acompanhamento de canções, considerando a percussão como forma de musicalização e também como forma de desenvolvimento psicomotor.

Em resumo, das 40 aulas, gravadas em vídeos, cedidas para esta pesquisa, somente sete serão efetivamente consideradas para análise (ver Tabela 2), a fim de se investigar a forma como a percussão está sendo trabalhada em aulas de música no ensino fundamental e, a partir disso, discutir estratégias de ensino e aprendizagem. 


\begin{tabular}{r|c|c}
\hline \multicolumn{1}{c|}{ AUTORES } & AULAS ANALISADAS & AULAS COM PERCUSSÃO \\
\hline Madeira (2012) & 05 & 00 \\
\hline Mateiro e Egg (2013) & 08 & 00 \\
\hline Madeira (2015) & 09 & 03 \\
\hline Vechi (2015) & 18 & 04 \\
\hline Total & $\mathbf{4 0}$ & $\mathbf{0 7}$ \\
\hline
\end{tabular}

Tabela 2: Gravações das aulas Fonte: autoras

\section{Transcrição e análise de vídeos}

O processo de análise de materiais audiovisuais implica, primeiramente, em decisões e escolhas. Rose (2004, p.343) esclarece que diferentes orientações teóricas levarão a diferentes escolhas, nunca havendo uma análise que capte uma verdade única do texto. A maior parte dos trabalhos gravados em áudio e vídeo são transcritos para serem analisados mais facilmente. A transcrição, de acordo com Rose (2004, p.348), tem como finalidade gerar um conjunto de dados em formato de texto para uma análise cuidadosa e possível codificação. Atualmente existem recursos tecnológicos - como por exemplo o ATLAS.ti - que permite realizar uma codificação direta do material gravado, mesmo com limitações, sem haver transformações no formato do texto (GARCEZ; DUARTE; EISENBERG, 2011, p.258).

Gibbs (2009), descreve que o desenvolvimento dos sistemas de gravação em áudio e vídeo podem reduzir a necessidade de transcrever estes materiais futuramente. Para o autor "o uso de dados em vídeo preserva alguns dos aspectos visuais dos dados que muitas vezes são perdidos durante a transcrição de conversações" (p. 17). De acordo com Garcez, Duarte e Eisenberg (2011, p. 256): "transcrever falas é possível, porém, por mais que se tente descrever com detalhes gestos, olhares e entonações da voz, cadências etc, imagens dificilmente podem ser transpostas para a linguagem escrita resguardando a devida precisão". Este fato pode ser visto como uma desvantagem do uso de vídeo, porém é um fator positivo para que os pesquisadores utilizem cada vez mais a vídeo-análise sem requerer a ferramenta da transcrição.

Segundo Pinheiro, Kakehashi e Angelo (2005, p. 720), o referencial e a escolha do tema também influenciarão na análise do vídeo. Os autores destacam que "para efetuar a análise do material filmado, é necessário, em primeiro lugar, selecionar as imagens e os discursos que são relevantes. Isso implica em escolhas e decisões que devem ser baseadas nos objetivos do estudo e no referencial teórico escolhido". Para a vídeo-análise deve-se considerar tanto a parte de áudio como de vídeo, contribuindo para a escolha metodológica e entendendo que o discurso e as imagens são fenômenos complexos e analisados como um único fenômeno. De qualquer maneira, a vídeo-análise deve ser feita de forma cuidadosa, reflexiva e criteriosa em constante avaliação.

As orientações e etapas destacadas pelos autores aqui expostos foram levadas 
em conta no processo de transcrição dos vídeos, considerando o objetivo desta pesquisa que é o de compreender como a percussão é trabalhada nas aulas da disciplina curricular Artes/Música. O material bruto realizado anteriormente pelas autoras Madeira (2012; 2015), Mateiro e Egg (2013) e Vechi (2015) foi também, gentilmente, cedido para este estudo para a complementação de informações.

\section{Coletividade, psicomotricidade, musicalização, imitação e escuta}

As práticas percussivas foram vivenciadas ressaltando o aspecto social, presente principalmente nas três aulas, conforme registradas por Madeira (2015). Normalmente, durante as aulas, as crianças sentavam-se em roda na sala de artes e instrumentos de percussão que eram disponibilizados pelo professor: tambores, ganzás (choca(hos), maracas, paus-de-chuva, caxixis. Durante essas aulas cantaram a cantiga Samba-Lelê e, em conjunto, reproduziram uma célula rítmica em instrumentos variados, além de ensaiarem um arranjo dessa canção para uma futura apresentação.

O senso de coletividade por meio da música está refletido no posicionamento constante das crianças sentadas em roda, bem como na execução conjunta de células rítmicas e na compreensão do que é um arranjo, quando assistiram vídeos de diferentes arranjos do Samba-Lelê: os Barbatuques, uma orquestra e um pianista. A aprendizagem ocorreu, portanto, em grupo e não individualmente. Nesse sentido, Freitas (2008) afirma que a percussão quando trabalhada em grupo, amplia a compreensão musical de todos os participantes da atividade.

Um exemplo pode ser visto na atividade de pergunta e resposta realizada em uma das aulas gravada por Madeira (2015, p.109). O professor monta um arranjo para a cantiga Samba-Lelê a partir da forma pergunta e resposta: na primeira vez, a cantiga inteira é cantada com acompanhamento do professor no pandeiro; na segunda, todos cantam a pergunta e tocam a resposta no instrumento; e, na terceira vez, a pergunta é realizada nos chocalhos e os tambores respondem. Small (1989, p.218) descreve esse fenômeno como um aspecto comunitário em música. Segundo o autor, isto ocorre quando a música é feita em conjunto, partilhada por duas ou mais pessoas. É desta maneira que a música passa a ser um encontro social, onde o caráter humano é valorizado e todas as pessoas envolvidas fazem parte do fazer musical, firmando laços, criando um forte senso de coletividade e estabelecendo relações pessoais através da música.

A forte presença da percussão, como um meio para a aprendizagem de conceitos musicais, deu-se em aulas voltadas para o aprendizado de compassos, pulsação, células rítmicas e acompanhamento de canções com percussão corporal, contextualizada com vídeos dos Barbatuques na maioria das aulas registradas, por Vechi (2015), em vídeo. Em uma das aulas os alunos aprenderam o ritmo da ciranda. O professor disponibilizou uma alfaia e três alunos foram chamados por vez para executarem a atividade: o primeiro tempo foi marcado na pele do tambor, marcando o tempo forte da ciranda, e os três restantes foram marcados no aro.

Nas aulas gravadas por Madeira (2015, p.105), a cantiga Samba-Lelê foi trabalhada com percussão, tendo como finalidade o ensino da música e não a técnica específica dos instrumentos. Através de um conjunto completo de ações que os instru- 
mentos de percussão proporcionam, de acordo com Chiarelli e Barreto (2005, p.3), a criança pode desenvolver o senso rítmico, aspecto importante na aprendizagem musical. Como a cantiga permite pergunta e resposta, a atividade proposta pelo professor sugeria contrastes e combinações de altura e timbre: vozes e percussão, vozes masculinas e vozes femininas, percussão (tambores) e percussão (chocalhos). Após o trabalho com a repetição da célula rítmica de Samba-Lelê a turma fez o jogo do eco: quem estava com o pandeiro criava uma frase e todos repetiam.

A diversidade de instrumentos disponibilizados nas aulas, em sua prática, desenvolvia a parte psicomotora das crianças. Paiva (2004, p.24) acrescenta que para tocar diferentes instrumentos são necessárias formas diferenciadas de manuseio e movimentos corporais, fazendo com que o aluno desenvolva habilidades específicas, transformando sua linguagem corporal e rítmica. Desta forma, durante as aulas registradas por Madeira (2015), as crianças experimentavam diversos tipos de instrumentos de percussão como, por exemplo, tambores variados, caxixi, pau-de-chuva, maracas e pandeiro, fazendo com que a exploração fosse constante através do revezamento de instrumentos. Já nas aulas de registradas em vídeo por Vechi (2015), o professor mostrou aos alunos o movimento para tocar ganzá, ensinando o manejo, a posição de como segurar e a técnica específica para tocar o referido instrumento.

A capacidade piscomotora foi também aprimorada durante as atividades de percussão corporal. Em um dos vídeos de Vechi (2015) o professor trabalhou as cantigas do boi-de-mamão durante a aula. A turma aprendeu a canção e o professou acompanhou com o violão e, posteriormente, ele ensinou a batida do boi para acompanhamento na percussão corporal. A batida ensinada aos alunos foi uma célula em que todos lembraram rapidamente o ritmo do rock: duas batidas no peito e uma palma. Esse processo de ensino e aprendizagem, como apontado no trabalho de Santos (2013), teve a corporalidade como elemento essencial, pois os alunos aprenderam ouvindo, observando e imitando.

Durantes as aulas observadas, a imitação e a escuta foram desenvolvidas durante a aprendizagem musical dos alunos por meio de atividades de repetição em tempo real como, por exemplo, na cantiga Samba-Lelê, nas aulas gravadas por Madeira (2015). Uma das aulas consistiu em relembrar a cantiga Samba-Lelê para depois reproduzirem a célula rítmica da melodia nos instrumentos (Figura 1). Para isso, o professor ensinava através da repetição, tocando no pandeiro a primeira frase e a turma respondia a segunda nos instrumentos de percussão, e assim sucessivamente. 


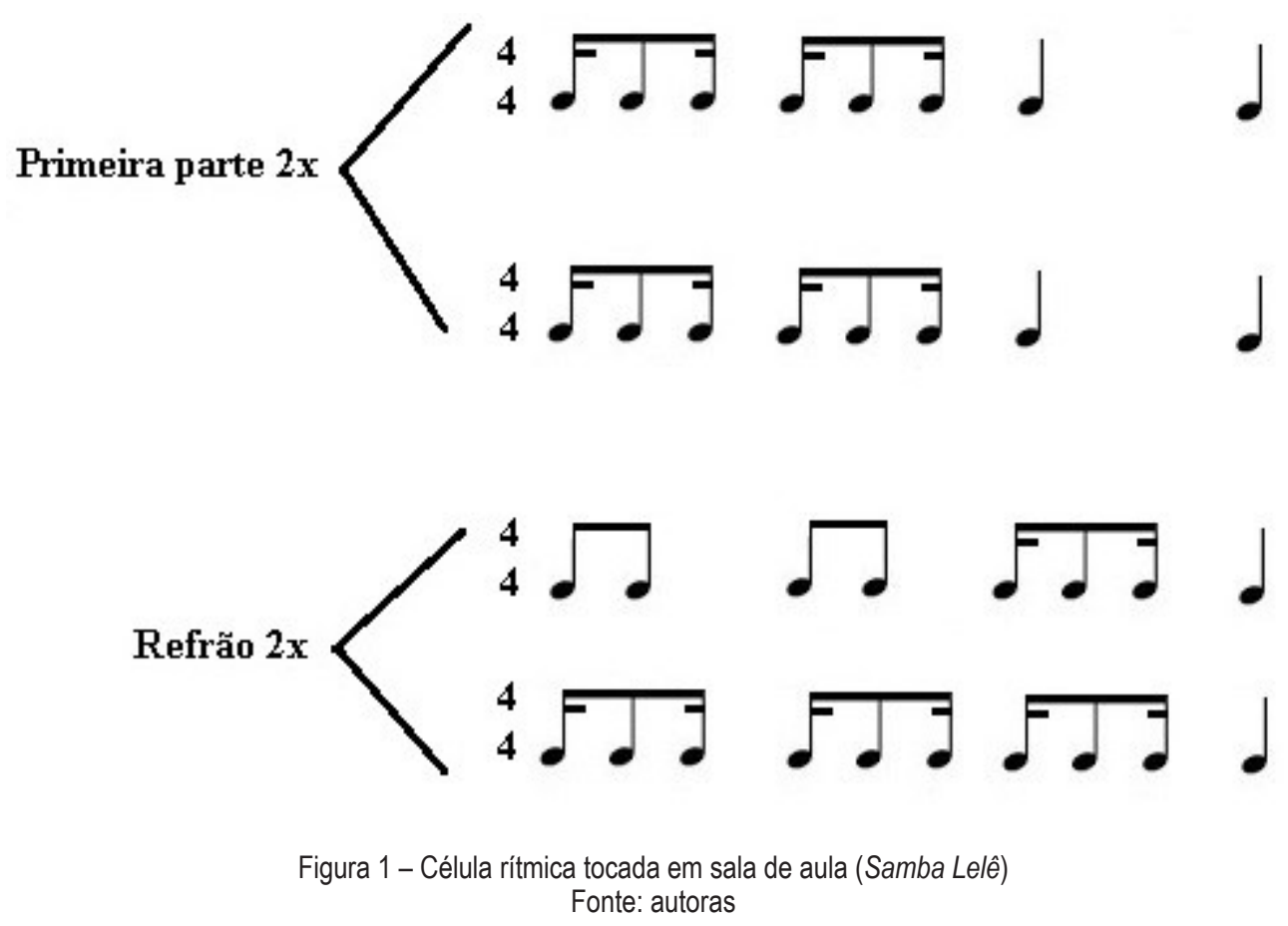

Os estudantes executavam essas células propostas pelo professor que estava ali presente como um exemplo, referência e meio de interação para os alunos. Como afirmam Baltazar e Freire (2012), o professor passou a ser o espelho e os alunos se sentiam mais seguros. Com isso, as frases eram executadas como um jogo de eco: pergunta feita pelo professor tocando a célula rítmica e resposta da turma fazendo a repetição.

Resumindo, constatou-se que os aspectos analisados nas aulas de música para a realização deste trabalho - coletividade, psicomotricidade, musicalização, imitação e escuta por meio da percussão, estiveram presentes nas aulas observadas e gravadas por Madeira (2015). Já nas aulas registradas por Vechi (2015) verificou-se somente a percussão como forma de desenvolvimento psicomotor e musicalização.

\section{Considerações Finais}

Este trabalho revelou que as atividades de percussão, sejam elas corporais ou com instrumentos, estão presentes em poucas aulas de música no contexto das escolas públicas de educação básica, pois de 40 aulas registradas em vídeo, apenas sete puderem ser consideradas para esta pesquisa. Vale destacar que dessas sete aulas, três são de uma escola de Florianópolis, onde observamos uma variedade de instrumentos e atividades diversas - o que pode nos levar a concluir que não só essa escola como outras escolas municipais dispõem de instrumentos de percussão para as aulas de música. As outras quatro aulas foram realizadas em escolas da Microrregião de Itajaí, onde a percussão corporal esteve mais presente.

Ter acesso a aulas de música por meio de vídeos tem suas limitações, entretanto, as gravações podem ser um recurso metodológico com fins didáticos, educacionais e investigativos. Os princípios da técnica da vídeo-análise empregados neste estudo possibilitou olhar para os dados com uma lente direcionada às práticas percussivas 
desenvolvidas em diversas aulas de música, de diferentes escolas públicas de cidades distintas. Vale destacar que não seria possível observar em poucos meses 40 aulas de música em diferentes locais e espaços, como de fato ocorreu com o acesso às gravações das referidas aulas para a realização deste trabalho. Ter os vídeos como método de pesquisa significou ter ações temporais e acontecimentos reais registrados por meio de imagem com acompanhamento de som que, apesar de serem restritos, retratam uma determinada realidade que não pode ser alterada.

Constatou-se, com a análise de dados dos vídeos coletados por Madeira (2015) e Vechi (2015), que a percussão foi utilizada em sala de aula, na maioria das vezes, como um caminho para outra finalidade, ultrapassando a ideia de se aprender a tocar instrumentos de percussão nas aulas de música como o principal objetivo. Os instrumentos de percussão não foram utilizados pelos professores a fim de trabalhar técnicas percussivas, ou seja, as atividades com canções trabalhavam a percussão como um acompanhamento rítmico ou também como um modo de adquirir a pulsação. Por outro lado, a diversidade de instrumentos possibilitou o compartilhamento das atividades, despertando a coletividade através da música, com momentos em que todos tocavam juntos e exploravam timbres, texturas e ritmos.

Trabalhar peças percussivas e técnicas prioritariamente no âmbito escolar pode ser outra maneira de desenvolver a musicalidade destacando a percussão como elemento principal. Porém, utilizar instrumentos de percussão para se pensar a música como um todo, já é de fato uma grande contribuição para os estudos percussivos nas escolas de educação básica. Foi dessa forma que os contextos analisados desenvolveram o ensino da música, tendo os instrumentos de percussão como um fator contribuinte, por meio da imitação e escuta, psicomotricidade, musicalização e coletividade. Além disso, percebeu-se que o trabalho com percussão auxiliou no desenvolvimento do conteúdo de música selecionado pelos professores nas atividades de sala de aula.

Espera-se que este estudo possa contribuir para área de educação musical e, mais especificamente, para a pesquisa acerca dos instrumentos de percussão e suas características de ensino e aprendizagem nas aulas curriculares de música dos diversos níveis de ensino da escola básica, assim como estimular educadores musicais a adotar práticas percussivas em suas aulas no contexto escolar.

\section{Referências}

BALTHAZAR, Laura Udihara, FREIRE, Ricardo Dourado. "A observação dos neurônios -espelho na performance musical: possibilidades de auxílio na iniciação musical instrumental." Anais do VIII Simpósio de Cognição e Artes Musicais - Florianópolis, 2012. Santa Catarina: PPGMUS-UDESC, p.3-10.

BEINEKE, Viviane. O conhecimento prático do professor de música: três estudos de caso.2000. 203f. Dissertação (Mestrado) Programa de Pós-Graduação em Música Universidade Federal do Rio Grande do Sul, Porto Alegre, 2000. 
BOHNSACK, Ralf. A interpretação de imagens segundo o método documentário. In: Vivian Weller; Nicolle Pfaff (orgs.). Metodologias da Pesquisa Qualitativa em Educação. Teoria e Prática. Petrópolis: Vozes, 2010, p.114-134.

BOLÃO, Oscar. Batuque é um privilégio. Rio de Janeiro: Lumiar Editora, 2003.

CHIARELLI, Lígia Karina Meneghetti; BARRETO, Sidirley de Jesus. A importância da musicalização na educação infantil e no ensino fundamental: a música como meio de desenvolver a inteligência e a integração do ser. Revista Recrearte, n. 3, p. 1-10, 2005. Disponível em http://www.iacat.com/revista/recrearte/recrearte03/musicoterapia.htm. Acesso em 25/10/2015.

DECKERT, Marta. Construção do conhecimento musical sob uma perspectiva piagetiana: da imitação à representação. Revista da $A B E M$, v. 16, n. 19, 2008, p.93-102.

FREITAS, Emília Maria Chamone de. O gesto musical nos métodos de percussão afro -brasileira. Dissertação (mestrado). Programa de Pós-Graduação em Música (PPGMUS) - Universidade do Federal de Minas Gerais, Belo Horizonte, 2008.

FRUNGILLO, Mário D. Dicionário de Percussão. São Paulo: Editora UNESP/Imprensa Oficial do Estado, 2003.

GARCEZ, Andrea; DUARTE, Rosalia; EISENBERG, Zena. Produção e análise de vídeogravações em pesquisas qualitativas. Educação e Pesquisa, v. 37, n. 2, p. 249-262, 2011.

GIBBS, Graham R. Análise de dados qualitativos: Coleção Pesquisa Qualitativa. Porto Alegre: Artmed S.A., 2009.

JACOB, Mingo. Método básico de percussão: universo rítmico. São Paulo: Irmãos Vitale, 2003.

LAMEIRA, Allan Pablo; GAWRYSZEWSKI, Luiz de Gonzaga; PEREIRA JUNIOR, Antônio. Neurônios Espelho. Psicologia USP, v. 17, p.123-133, 2006.

LEITÃO, Lúcia Irala; TEIXEIRA, Pedro Fernando Dorneles; DA ROCHA, Fábio Saraiva. A vídeo-análise como recurso voltado ao ensino de física experimental: um exemplo de aplicação na mecânica. Revista Electrónica de Investigación en Educación en Ciencias, v. 6, n. 1, p. 18-32, 2011.

LOIZOS, Peter. Vídeo, filme e fotografias como documentos de pesquisa. In: Martin W. Bauwer; George Gaskell (orgs.). Pesquisa Qualitativa com Texto, Imagem e Som: Um Manual Prático. 3ª ed. Petrópolis, RJ: Vozes, 2004, p.137-155.

MADEIRA, Ana Ester Correia. Todo professor é um herói: o professor e a motivação 
na aula de música. Trabalho de Conclusão de Curso (graduação) - Universidade do Estado de Santa Catarina, 2012.

MADEIRA, Ana Ester Correia; MATEIRO, Teresa. Motivação na aula de música: reflexões de uma professora. Percepta, v.1. n.1, p.67-82, 2013.

MADEIRA, Ana Ester Correia. Professor pesquisador: análise, reflexão e mudança na aula de música. Dissertação (mestrado). Programa de Pós-Graduação em Música (PPGMUS) - Universidade do Estado de Santa Catarina, Florianópolis, 2015.

MARCELINO, André Felipe. Grupo de maracatu Arrasta Ilha: dinâmicas de aprendizagem musical em uma comunidade de prática. Dissertação (Mestrado em Música - Educação Musical). Universidade do Estado de Santa Catarina. Programa de Pósgraduação em Música, Florianópolis, 2014.

MATEIRO, Teresa; EGG, Marisleusa de Souza. O canto na aula de música: reflexões sobre uma prática em uma escola pública. In: FÓRUM DE PESQUISA EM ARTE, 9., 2013, Curitiba. Anais... Curitiba: ArtEmbap, p. 204-215, 2013.

MATEIRO, Teresa (org.). Publicações da Associação Brasileira de Educação Musical. Indíce de Autores e Assuntos 2006-2012. Florianópolis: UDESC, 2013.

MOREIRA, Thiago Alves Marques. "Transformar música": o conhecimento pedagógico do conteúdo de um professor de violão. Dissertação (mestrado). Programa de Pós-Graduação em Música (PPGMUS) - Universidade do Estado de Santa Catarina, Florianópolis, 2014.

MOURA, Maria Lúcia S. de; RIBAS, Adriana, F. P. Imitação e desenvolvimento inicial: evidências empíricas, explicações e implicações teóricas. Estudos de Psicologia, v.7. n.2, p.207-215, 2002.

MÜLLER, Vânia Beatriz; HAHN, Gabriel Peplau. A vivência musical de crianças e adolescentes: performance através da percussão. In: In: ENCONTRO ANUAL DA ASSOCIAÇÃO BRASILEIRA DE EDUCAÇÃO MUSICAL, 14, 2005, Belo Horizonte. Anais... Belo Horizonte: ABEM, 2005. p.01-07. CD-ROM

MÜLLER, Vânia. Oficina de percussão: vivência musical e prática pedagógica. In: ENCONTRO ANUAL DA ASSOCIAÇÃO BRASILEIRA DE EDUCAÇÃO MUSICAL, 14, 2005 , Belo Horizonte. Anais... Belo Horizonte: ABEM, 2005. p.01-07. CD-ROM

PACHECO, José Augusto. O pensamento e a acção do professor. Porto: Porto Editora, 1995.

PAIVA, Rodrigo Gudin. Percussão: uma abordagem integradora nos processos de ensino e aprendizagem desses instrumentos. Dissertação (mestrado). Programa de Pós- 
Graduação em Música - Universidade Estadual de Campinas, Campinas, 2004.

PINHEIRO, Eliana Moreira; KAKEHASHI, Tereza Yoshiko; ANGELO, Margareth. O uso de filmagem em pesquisas qualitativas. Revista Latino-Americana de Enfermagem, v. 13, n. 5, p. 717-722, 2005.

ROSE, Diana. Análise de imagens em movimento. In: Martin W. Bauwer; George Gaskell (orgs.). Pesquisa Qualitativa com Texto, Imagem e Som: Um Manual Prático. 3a ed. Petrópolis, RJ: Vozes, 2004, p.343-366.

ROSSATTO, Viviane Cristina; CAMARGO, Janira Siqueira. A arte de brincar com a percussão corporal. In: PARANÁ. Secretaria de Estado da Educação. Superintendência de Educação. O Professor PDE e os desafios da escola pública paranaense, 2010. Curitiba: SEED/PR, 2010, Vol.1 (Cadernos PDE). Disponível em http://www.diaadiaeducacao.pr.gov.br/portals/cadernospde/pdebusca/producoes_pde/2010/2010_uem_ edespecial_artigo_viviane_cristina_rossatto.pdf. Acesso em 25/10/2015.

SAMPAIO, Luiz Roberto; BUB, Victor Camargo. Pandeiro Brasileiro, vol. 1. Florianópolis: Editora DPX, 2014.

SANTOS, Catherine Furtado. Casa Caiada: formação humana e musical em práticas percussivas colaborativas. Dissertação (Mestrado). Programa de Pós-Graduação em Educação Brasileira. Universidade Federal do Ceará, Fortaleza, 2013.

SCHAFER, Murray. O ouvido Pensante. São Paulo: Editora UNESP, 1991.

SCHRADER, Erwin. Expressão musical e musicalização através de práticas percussivas coletivas na Universidade Federal do Ceará. Tese (Doutorado em Educação). Programa de Pós-Graduação em Educação Brasileira. Universidade Federal do Ceará, Fortaleza, 2011.

SLOBODA, John. A mente musical: a psicologia cognitiva da música. Londrina: EDUEL, 2008.

SMALL, Christopher. Musica, sociedad, educación. Madrid: Alianza Editorial, 1989.

SOUZA, Jusamara. Música em projetos sociais: a perspectiva da sociologia da educação musical. In: Jusamara Souza; Magali Kleber, Antônio Dias Nascimento et al. (orgs). Música, educação e projetos sociais. Porto Alegre: Tomo Editorial, p. 11-26, 2014.

SOUZA, Henry Raphaely. Processos de ensino coletivo de bateria e precussão: reflexões sobre uma prática docente. Dissertação (mestrado). Programa de Pós-Graduação em Música (PPGMUS) - Artes, Universidade do Estado de Santa Catarina. Florianópolis, 2012. 
STANLEY, Sadie. Dicionário Grove de Música. Rio de Janeiro: Jorge Zahar Editora, 1994.

PACHECO, José Augusto. O pensamento e a acção do professor. Porto Editora: Portugal, 1995.

TRALDI, Cesar; CAMPOS, Cleber; MANZOLLI, Jônatas. Performance Mediada \& Percussão Múltipla. In: CONGRESSO DA ANPPOM, 16, 2006, Brasília. Programa de PósGraduação Música em Contexto. Brasília: Editora Universidade de Brasília, p.10321038, 2006.

ULLER, Andrei Jan Hoffmann. Processos de ensino de violão em escolas livres de música: um estudo de caso das práticas pedagógicas de dois professores. Dissertação (mestrado). Programa de Pós-Graduação em Música (PPGMUS) - Artes, Universidade do Estado de Santa Catarina. Florianópolis, 2012.

VECHI, Hortênsia. O canto na formação e na aula de música: três estudos de caso. Dissertação (mestrado). Programa de Pós-Graduação em Música (PPGMUS) - Universidade do Estado de Santa Catarina, 2015.

WEILAND, Renate Lizana; VALENTE, Tamara da Silveira. Aspectos figurativos e operativos da aprendizagem musical de crianças e pré-adolescentes, por meio do ensino de flauta doce. Revista da ABEM, v. 15, n. 17, 2007. 